\title{
Lola Casanova: la Malinche invertida en la cultura nacional mexicana
}

Robert McKeE IRWin

Universidad de California, Davis

La leyenda de Dolores Casanova y Coyote Iguana es una historia fronteriza que desafía los límites del imaginario nacional en México. Lola ha sido una figura inquietante para los mexicanos que conocen su leyenda desde que entró en el discurso público en 1850; ha permanecido así desde entonces, aunque pocos mexicanos saben quién es. Este estudio esboza la trayectoria de la leyenda de Lola Casanova y medita su inconformidad con la ortodoxia nacional de identidad racial en México.

Todo empezó el 23 de febrero de 1850. Varias fuentes ubican estos eventos años o hasta décadas después, ${ }^{1}$ pero la única fuente primaria, una carta fechada el 25 de febrero de 1850 del coronel Cayetano $\mathrm{Na}$ varro, prefecto de Guaymas, a José de Aguilar, gobernador de Sonora, desmiente estas revisiones. El año es importante. Sitúa los acontecimientos sólo dos años después de que los invasores estadunidenses se retiraron de México al terminar la guerra de 1846-1848. Sonora, siempre territorio de frontera —en el sentido de la palabra inglesa frontier: zona alejada del corazón poblado del país y todavía no bien incorpo-

\footnotetext{
${ }^{1}$ Por ejemplo, en 1995 el cronista sonorense Gilberto Escobosa Gámez ubica los acontecimientos en el año 1854, fecha corroborada por la primera representación histórica de la leyenda, recontada por Fortunato Hernández (1902) y repetida en varias otras relaciones, entre ellas, la novela histórica Cajeme (1948) de Armando Chávez Camacho. Otro cronista sonorense, Fernando Galaz (1960), coloca la leyenda en la primavera de 1872, mientras que Carmela Reyna de León, en su novela histórica Dolores o la reina de los kunkaks (1943), provee la fecha de 1879.
} 
rada en la cultura nacional - ahora se halló precisamente en la línea fronteriza con los Estados Unidos. ${ }^{2}$ El territorio de repente se volvió más vulnerable, condición aprovechada en la década siguiente por una serie de invasores filibusteros, quienes habían identificado el noroeste de México como el próximo proyecto de explotación estilo Alta California. $^{3}$

Su vulnerabilidad se debía a su estado de despoblación, problema exacerbado por la presencia antagónica de varios grupos indígenas no asimilados y en algunos casos nunca verdaderamente conquistados, incluyendo no sólo los apaches ${ }^{4}$ — que radicaban principalmente en el lado estadunidense de la frontera y que se volvieron notorios por asaltar colonias mexicanas, robando abastecimientos que después vendían en los Estados Unidos- sino también yaquis, mayos y seris insurgentes, con quienes México se mantendría en estado de guerra hasta las primeras décadas del siglo xx. ${ }^{5}$ La frontera noroeste de México en 1850 en efecto compartía más con Alta California y el antiguo oeste de los Estados Unidos de lo que tal vez se imaginara: las dos eran fronteras todavía poco explotadas, las dos promovidas en ese entonces como territorios de gran potencialidad para el desarrollo económico y la colonización, pero también eran zonas de conflicto violento entre los colonizadores, blancos en su mayoría —o por lo menos, en el caso mexicano, mestizos aculturados a la cultura criolla-, y los pueblos indígenas no sometidos de la región. Las diferencias entre la frontera noroeste de México y la suroeste de Estados Unidos eran principalmente económicas. La fiebre de oro ya impulsaba una rápida coloniza-

${ }^{2}$ La noción de "frontier" como zona impulsora de colonización, expansión y explotación tiene importancia enorme en la historia estadunidense (Turner). Su papel en México también ha recibido merecida atención, primero en un ensayo provocador del historiador mexicano Silvio Zavala en 1965, luego en el trabajo de Alistair Hennessy (1978) y más recientemente con las investigaciones interesantes de David Weber (ver, por ejemplo su introducción, escrita en colaboración con Jane Rausch, a Where Cultures Meet: Frontiers in Latin American History de 1994).

${ }^{3}$ Aparte de la conocida retórica expansionista del "destino manifiesto" en Estados Unidos (Rippy: 85-105, Ruibal Corella: 125-133), existía en la imaginación francesa una leyenda dorada de la región que también inspiró proyectos imperialistas franceses (López Yescas).

${ }^{4}$ Sobre cuestiones de conflictos fronterizos causados por los apaches, ver Jones, especialmente la página 112 .

${ }^{5}$ Véase Figueroa Valenzuela. 
ción y expansión económica en el lado estadunidense, atrayendo ya migraciones de mexicanos (juntos con aventureros de todo el mundo) hacia el norte, y provocando crisis de despoblación en el noroeste mexicano. ${ }^{6}$ Mientras tanto, por la retórica del "destino manifiesto", las menos frecuentes migraciones en la otra dirección provocaban a menudo preocupaciones de maquinaciones imperialistas. ${ }^{7}$

Mucho ha sido escrito recientemente sobre el otro lado (el estadunidense) de la frontera en estos primeros años de la posguerra por los apóstoles de los "New American Studies", Estudios Chicanos o Estudios de la Frontera. El contexto complejo en el que sucedió la historia de Lola Casanova señala lo productivo que será orientar la atención crítica al lado mexicano también — lado ignorado en gran parte por la academia estadunidense-, y no sólo para ver la historia de Sonora como un fragmento de la historia nacional mexicana, sino para reinterpretar la región desde la perspectiva "transamericana" o "interamericana" propuesta por algunos "americanistas" contemporáneos (Sommer: 221-232). A pesar de que la meta de este estudio es interpretar la leyenda de Lola Casanova en un entorno nacional, el contexto fronterizo en el que surgió exige una consideración de su contexto transamericano.

Volviendo entonces a la historia, en febrero de 1850 viajaba la joven Dolores Casanova de su casa en Guaymas a Hermosillo, cuando su diligencia fue asaltada por una banda de "indios bárbaros", ${ }^{8}$ quienes mataron a su padre y a todos los demás viajeros menos a Lola, a quien raptaron. El cuento empieza en el estilo típico de la narrativa de cauti-

${ }^{6}$ Escribe el historiador José Antonio Ruibal Corella: "la fiebre de oro fue de nefastas consecuencias a corto y mediano plazo. En efecto, como la actual Baja California se encontraba prácticamente despoblada, los mexicanos más próximos a los placeres eran... los sonorenses" (115). Estima que "conservadoramente [...], es válido calcular que la décima parte de los habitantes de Sonora emigraron a California" en esa época (116).

${ }^{7}$ Asevera Ruibal Corella: "De 1852 a 1857 Sonora se vio conmocionada por sucesivos intentos filibusteros que trataron de segregar su territorio para ofrecerlo en venta al país del aventurero en turno. Fueron episodios sumamente graves para la marcha del Estado, que mantuvieron en permanente psicosis a sus habitantes y prácticamente ocupada la atención de toda la entidad" (137).

8 Término usado por lo común para referirse no a todos los indígenas, sino a los grupos enemigos de los criollos. Ver, por ejemplo, Aldaco Encinas y Weber. Para un estudio sobre las sutilezas de identidad racial en el noroeste de México en el siglo XIX, ver Radding. 
verio de la frontera americana. ${ }^{9} \mathrm{La}$ amenaza implícita en las relaciones de raptor indígena y cautiva blanca siempre era sexual: era lo que Susana Rotker llama "el complejo de Próspero": "el terror al día en que el de abajo quiera tomar venganza y la secreta sospecha de que el furioso cuerpo de este inferior violará a su hija" (45); es decir, un miedo a la potencial violación de la América blanca por la salvaje América indígena. Estas narrativas a menudo terminaban con un rescate heroico o un escape milagroso, muchas veces seguido por una venganza sangrienta de parte de los blancos. En el peor caso, culminaban en tragedia con las cautivas esclavizadas, torturadas o hasta asesinadas. Se contaban para justificar los proyectos de conquista o incluso de genocidio. ${ }^{10}$

Si México era ya una nación mestiza que había incorporado si no biológicamente, por lo menos culturalmente, a gran parte de su población indígena, los conflictos continuos en sus zonas fronterizas, especialmente en el norte y el sur, señalaban la pertinencia de la leyenda de Casanova a la vida cotidiana de algunos mexicanos decimonónicos - los fronterizos. Los asaltos de los "indios bárbaros", sus robos, raptos, violaciones y asesinatos de desamparadas doncellas blancas todavía los impactaban demasiado.

Lo que más llamó la atención del caso de Casanova, sin embargo, fue su desenlace. El pelotón de salvamento se suspendió sin conseguir su rescate, aun cuando localizaron a Lola y fueron por ella $-\mathrm{y}$ no porque los seris la detenían de rehén, sino porque resultaba que ella no quiso volver a Guaymas-. Se había enamorado — según la interpretación clave que hacen las versiones modernas de la leyenda- del jefe Coyote Iguana, a pesar de la participación de éste en el asalto sangriento en el que murió el padre de la joven. Ya era la esposa de aquel "salvaje", y pronto sería madre de su primer hijo, un futuro jefe mestizo de los seris. ${ }^{11}$

\footnotetext{
${ }^{9}$ Me refiero tanto a la frontera norteamericana (Faery) como a las varias fronteras latinoamericanas (Operé, Rotker).

${ }^{10}$ Un texto fundacional del género es la narrativa de la puritana inglesa Mary Rowlandson del siglo XVII, analizada por Faery: 19-79. En América Latina, el ejemplo clásico es La cautiva del argentino Esteban Echevarría de 1837, analizado por Rotker: 115-46.

${ }^{11}$ Aunque el amor interracial es premisa clave en las versiones literarias y cinematográficas de la leyenda, algunos autores no eran capaces de concebirlo, y prefirieron representar la decisión de Lola de quedarse con Coyote Iguana como consecuencia
} 
La historia de Lola casi no tuvo presencia en la escritura de la época. El único periódico sonorense en circulación en estos años fue El Sonorense, publicación oficial que se editaba en la capital estatal de Ures. Dedicado principalmente a la difusión de documentos y comunicaciones gubernamentales (leyes, proclamaciones, discursos oficiales, etc.), tenía poco espacio para noticias. Sin embargo, bajo el titular "Seris", mencionó dos veces (el 3 de mayo y el 7 de junio de 1850) el caso del asalto a la diligencia en la que viajaba Lola. Sólo la segunda vez, nombra directamente a Dolores Casanova al aseverar que a ella le habían "pacificado en el cautiverio" los seris. Es la única frase publicada que se refiere explícitamente a ella en el siglo XIX, pero lo inaudito del detalle garantiza que no se olvide.

Aparte del periódico oficial, no había periódicos en Sonora hasta años después, ${ }^{12}$ mucho menos editoriales que publicaban libros. ${ }^{13}$ La cultura regional de Sonora era en muchos sentidos una cultura oral - lo cual no quiere decir que los sonorenses eran analfabetos, sino solamente que la imprenta todavía no ejercía mucha influencia allí-. En ausencia de una cultura de escritura y lectura, la historia oral asumía más importancia. La leyenda de Lola Casanova se contaba en este ámbito sin tomar la forma fija de la escritura y sin incorporarse tampoco en la "literatura nacional", como sí ocurrió en el caso de otras leyendas de zonas más céntricas. ${ }^{14}$ Lola protagonizó un episodio de la historia local, el que comunicaba y hacía perdurar ciertos mensajes culturales

natural del instinto maternal, "una muestra de lo complejo de la psicología femenil, del cariño y martirio de madre, del misterio que envuelve a ese delicado ser llamado mujer" (López).

12 De hecho, se publicaron, durante cortos periodos, tres periódicos en Guaymas durante el año 1845, pero después de esto, no se estrenó otro hasta 1870. El caso de Hermosillo es similar. Se publicaron tres periódicos en el año 1846, pero no hubo otro hasta el año 1865 (Moncado: 222-240).

${ }^{13}$ La primera publicación de un libro literario en Sonora fue Heroína, obra de teatro del periodista Aurelio Pérez Peña, en 1897.

14 Por ejemplo, los bandidos legendarios se celebraban y se nacionalizaban en novelas como Astucia (1865) de Luis Inclán, Los bandidos del Río Frío (1891) de Manuel Payno y El Zarco (1901) de Ignacio M. Altamirano; mientras que el amor interracial entre la Malinche y Hernán Cortés se presentaba como mito fundacional de la nación en novelas como Los mártires de Anahuac (1870) de Eligio Ancona y Amor y suplicio (1873) y Doña Marina (1883) de Ireneo Paz. Ver Cypess y también el análisis de Maarten van Delden en ese volumen. 
tanto entre los criollos urbanos de Guaymas y Hermosillo como entre los seris de la Isla del Tiburón.

Ésta es una pequeña isla ubicada en el Golfo de California, donde se establecieron muchos de los seris, tribu nómada por tradición, después de perder el acceso libre a sus terrenos ancestrales en la zona noroeste del estado de Sonora. Allí en la Isla del Tiburón vivía Lola con su raptor vuelto marido, Coyote Iguana. Y allí tomó su leyenda una forma distinta de la versión que repetían los criollos y mestizos de Guaymas.

El mensaje cultural era indudablemente disimilar en los dos casos; pero sin evidencias escritas de la época sólo se puede especular sobre sus precisas implicaciones decimonónicas. En el caso estadunidense, concluye Rebecca Blevins Faery:

Historias de blancos raptados por indios, especialmente las de cautiverios de mujeres, contribuyeron en forma significativa a la producción de la diferencia, al principio cultural pero después racial, en la que las historias de rivalidades entre hombres 'rojos' y hombres 'blancos' se fundamentaron y la que se volvió la justificación principal de la conquista europea e impulsó el surgimiento de una nación fundada en una doctrina de la supremacía del hombre blanco (10; traducción mía).

Según Fernando Operé, el caso hispanoamericano no resulta muy distinto:

El cuerpo de la mujer asume el papel de depositario de las virtudes asignadas a la civilización cristiana. Su violación representa, no sólo la mayor afrenta contra lo más sagrado de sus principios, sino que sirve para corroborar la incontrolable sensualidad salvaje del indio agresor. La tergiversación del discurso civilizador fue capaz de invertir los términos del litigio transformando a las víctimas, los indios americanos, en agresores usurpadores de lo más preciado de la civilización cristiana, la mujer blanca (32).

Estas dos citas se refieren, sin embargo, a casos más típicos de narrativas de cautiverio, casos en los que la mujer está dispuesta a regresar a su familia y al pueblo "civilizado". La leyenda de Lola, por el hecho de que la joven se quedó con los seris por su propia voluntad, complica la interpretación. Puede ser que se haya repetido entre los blancos y mestizos de Sonora para mostrar la severidad de la amenaza de los 
"indios bárbaros". Es decir que la leyenda pudo haber circulado para intensificar el interés en el proyecto de derrotar a todos los grupos insurrectos de indígenas de la región, pero también pudo haber comunicado una idea subversiva: la noción de que la cultura criolla no era tan superior a la indígena y que los seris y otros grupos no eran tan salvajes como sus imágenes en la prensa decimonónica de Sonora.

Esta última idea indudablemente se comunicaba en las versiones seris de la leyenda. Aunque no hay evidencias concretas de la forma de la leyenda de Casanova entre los seris en el siglo XIX, es probable que las versiones grabadas en el siglo XX — discutidas más adelante- no sean muy distintas con respecto a las actitudes que presentan hacia el enemigo blanco. Lola Casanova era para los seris botín de guerra, evidencia material de una victoria de batalla. Además, el hecho de que la bella dama prefería vivir con ellos y no con su pueblo, y que optaba por casarse con Coyote Iguana y no con un prócer "yori" 15 mostraba la superioridad de la cultura seri. La noción de mestizaje implicada en el nacimiento de su hijo es una alegoría de integración nacional, pero no para una nación mestiza mexicana sino para la seri - y en esto se halla el aspecto más contundente de la leyenda de Lola Casanova-.

La idea fundamental del mestizaje que se conoce en México —el paradigma que ya se reiteraba en la literatura mexicana desde $1820 \_{ }^{16}$ era la que representa el lazo interracial entre la notoria Doña Marina, la Malinche, ${ }^{17}$ y Hernán Cortés, visto frecuentemente como la violación del México indígena por la Europa blanca. ${ }^{18}$ El mestizaje, según esta metáfora bien conocida - lugar común no sólo en México sino en las Américas en general, repetido, por ejemplo en las historias de Poca-

\footnotetext{
${ }^{15}$ Término (de origen yaqui) para referirse a los blancos o no indios, empleado en Sonora (Santamaría 1137).

${ }^{16}$ Me refiero a la novela Jicotencal (1826) (citada a veces con la ortografía náhuatl más correcta como Xicoténcatl), recientemente atribuida al cubano José María Heredia (González Acosta). Hubo tres obras de teatro publicadas en Puebla en el decenio de los veintes del siglo XIX basadas en esta novela: Xicohtencatl (1828) de José María Moreno y Buenvecino, Teutila (1828) de Ignacio Torres Arroyo y Xicoténcatl (1829) de José María Mangino (Cypess: 44).

17 Para la diversidad de interpretaciones culturales de esta figura, ver van Delden.

${ }^{18}$ Esta imagen está analizada en el ensayo clásico de Octavio Paz, "Los hijos de la Malinche". Ver también la discusión crítica sobre este mito fundacional del mestizaje nacional en Lomnitz: 52-54.
} 
hontas en Estados Unidos e Iracema en Brasil- ${ }^{19}$ implica unas configuraciones importantes de relaciones sociales. No sólo es el México indígena subordinado, privado de fuerza de voluntad, violado por la España "blanca", sino que también este lazo sexual, violentísimo, sujeta la cultura indígena a la española $-\mathrm{y}$ no al revés-. La joven Malinalli aprende español, asume un nombre español, y se empeña en asimilarse a la cultura española. No regresa a su pueblo, sino que lo abandona por el de su opresor. ${ }^{20} \mathrm{Su}$ violación, por lo tanto, implica nada menos que la aniquilación de su cultura.

A pesar del hispanismo que estaba más o menos de moda en ciertos momentos del siglo XIX, el liberalismo decimonónico estableció su visión de la mexicanidad reconociendo y censurando la crueldad y la codicia de los conquistadores españoles. Empezaba — tanto con la literatura ya mencionada de liberales como Ireneo Paz y Eligio Ancona, como con la pintura de neoclasicistas como José Obregón y Rodrigo Gutiérrez- a rescatar el pasado indígena como base cultural de la nación, proyecto que se desarrollaría mucho más con el indigenismo posrevolucionario. Empero nunca se les ocurrió a los liberales rechazar la influencia española y europea en la cultura mexicana. La europeización cultural de México seguía significando su civilización y su modernización. De hecho, para finales del siglo, los científicos porfirianos se iban preocupando por los "atavismos" de la cultura prehispánica en el México moderno del porfiriato. ${ }^{21}$ Lo indígena pertenecía al pasado mexicano y el proyecto de modernización requería la aculturación total de los indios.

Una solución del porfiriato fue "empantalonar" a los indios, es decir, vestirlos como europeos para quitarles sus atavismos bárbaros. Sur-

${ }^{19}$ Por supuesto que los usos culturales de estas figuras no son siempre idénticos. Ver, por ejemplo, la comparación que hace Christopher Dunn entre los significados de Pocahontas e Iracema en los contextos muy distintos de Estados Unidos y Brasil.

${ }^{20}$ Hay otro personaje simbólico del mestizaje cuya historia no se repite mucho: Gonzalo Guerrero, el español que se incorpora en la cultura maya antes de la llegada de Cortés y que se conoce como "el padre del mestizaje mexicano" (Mueller: 138).

${ }^{21}$ En su estudio La génesis del crimen en México (1901) — libro citado por Roger Bartra como fundacional en el proyecto de la búsqueda de la identidad nacional que después de la revolución asumió un papel central en los escritos de Samuel Ramos y Octavio Paz, entre otros-, Julio Guerrero elabora una unidad de doce capítulos titulada "Los atavismos", que culmina con el capítulo "Reaparición atávica de los sacerdotes de Huitzilopochtli”. 
gió una polémica en varias ciudades mexicanas por la presencia cada vez más visible de hombres indígenas en las calles de la ciudad, hombres que vestían prendas tradicionales, que para la élite capitalina no eran otra cosa que calzoncillos (González Navarro: 396-397). ${ }^{22}$ Esta polémica fue sinécdoque de la cultura mexicana (criolla y mestiza) en general, cuyo pasaje a la modernidad se consideraba imposible hasta que se eliminaran sus elementos primitivos (es decir, los indígenas). El hecho de que la leyenda de la Malinche se haya arraigado tanto, no sorprende entonces, ya que fomenta esta misma actitud hacia lo indígena.

Hasta el caso de Ignacio M. Altamirano, pese a sus diferencias radicales de la ortodoxia malinchista, finalmente la reafirma con la complicidad del propio letrado "indígena”. Altamirano, el gran promotor de literatura nacional del siglo XIX (Martínez: 145-202; Blanco: 41-51), se conocía y sigue conociéndose como "indio", a pesar del hecho poco conocido de que su madre era una mestiza de tez pálida y ojos claros (Campuzano: 12). Era indígena porque como indígena se educó y no aprendió el español sino hasta la adolescencia, y además porque la configuración racial de su familia — padre indígena casado con madre mestiza (que aparentaba ser blanca) y no madre indígena casada con padre blanco- no tenía modelo en el imaginario nacional. En su gran novela de alegoría nacional de integración racial (Sommer: 221-232), El Zarco (escrita a finales de los 1880, publicada en 1901), su protagonista indígena se admite como héroe entre sus lectores en gran parte criollos porque está asimilado cien por ciento a la cultura criolla. Se casa con la bella mestiza, Pilar, repitiendo el paradigma heterodoxo de los padres del propio autor. Altamirano reivindica al indio, acomodándolo en la cultura nacional, pero a la vez aniquila lo indio, excluyéndolo totalmente de su novela. No obstante que Altamirano identifica al protagonista específicamente como "tipo indígena bien marcado" (11), también describe el pueblo donde vive así: "La población toda habla español, pues se compone de razas mestizas. Los indios puros han desaparecido allí completamente" (4). Parece que hay dos definiciones de raza en operación en el texto, una que se basa en la sangre o apariencia física, y otra que se basa en la cultura. Un indígena aculturado sigue siendo indígena físicamente, pero ya no lo es culturalmente.

${ }^{22}$ El mismo género de polémica se dio en la Ciudad de México, Aguascalientes, San Luis Potosí, Colima y Jalisco. 
Parece que Altamirano favorece, al final, la segunda definición; pero en cuanto a la configuración de mestizaje que presenta la novela, a pesar de la inversión de papeles de género (ahora es el hombre y no la mujer el que representa la raza indígena), el resultado sigue siendo el mismo: lo indígena se subsume a lo europeo.

De ahí la radicalidad de la leyenda de Lola Casanova. No sólo invierte los papeles de raza y género respecto del paradigma malinchista —Lola, mujer blanca, se alía con el enemigo, un guerrero indio- sino que también invierte los flujos culturales subordinando la cultura criolla — rechazada por Lola - a la indígena. No trae a su marido seri a casa, ni lo viste en levita, ni le enseña español; al contrario, ella renuncia su lugar en la sociedad criolla para vivir con él, se viste como seri, aprende costumbres de su cultura, y se empeña en dominar su idioma: se deja "pacificar". Ésta es otra razón por la que la historia de Lola Casanova, por original o fascinante que sea, se mantiene fuera de la cultura escrita por tantos años. ${ }^{23}$

Es sólo en el año de 1902 cuando el historiador Fortunato Hernández se entera de su leyenda y la incluye como episodio de interés local en su historia de conflictos entre los criollos sonorenses y los indígenas de la región, Razas indígenas de Sonora y la guerra del Yaqui. Lola Casanova encuentra su lugar en la historia oficial — local y no nacionalcincuenta y dos años después de que su leyenda comenzara a circular oralmente dentro del estado, pero permaneciendo desconocida fuera de éste.

Lola, para Hernández, no es traidora sino víctima $-\mathrm{y}$ víctima no de los seris sino de su propio estado de mujer-. Después de relatar la historia de Lola, la que le llegó por medio de una informante, una sirvienta anciana llamada María, éste proporciona una interpretación "científica": "[l]a mujer nace hembra, y nada más. Amor, educación, afectos y cariño, deseos, actos, instintos, voliciones y sueños: todo en la vida de la hembra está subalternado a la actividad funcional del órgano que la diferencia y la caracteriza" (64). La particularidad de la hembra es, por supuesto, su instinto maternal.

${ }^{23}$ Aparte de la brevísima mención en El Sonorense, citada anteriormente, afirma Edith Lowell (quien no había consultado esta fuente) que "[n]inguna relación publicada de esta versión de la historia mexicana tradicional [de Casanova] se ha localizado" (145). 
Tan sólo así se explica que una mujer nacida y educada en plena civilización, haya podido adaptarse a un medio tan salvaje como el constituido por las costumbres seris, y abandonando patria, familia, hogar, religión, sociedad, presente, pasado y porvenir, se haya consagrado a vivir para el macho salvaje que logró sorprender, dominar y satisfacer sus inclinaciones sexuales, y haya sentido por él y por sus hijos ese sublime amor que eleva la hembra a la categoría de madre (65).

Hernández, en la primera interpretación histórica de la leyenda, se obsesiona por defender la civilización. Lola optó por lo bárbaro no por el raciocinio, sino por el salvajismo innato en la "hembra".

A diferencia de la lógica según la cual la Malinche se asimiló a la cultura española - porque era obviamente superior a la barbaridad de su gente-, la asimilación de Lola Casanova a la cultura seri significa la barbaridad de la mujer, cualquiera que sea su raza. La mujer — ser poco más evolucionado que un animal — está a gusto con "el macho salvaje”. No permite Hernández que la leyenda invierta la jerarquía cultural. El hecho de que este libro identifique al presidente mexicano Porfirio Díaz como "pacificador de México" muestra que su perspectiva es poco diferente de la de los colonizadores de la época de Lola Casanova. Los yaquis, los mayos, los apaches y los seris no eran más que enemigos del progreso y de la nación.

No obstante su presentación regionalista, la publicación del libro de Hernández en el Distrito Federal difundió la leyenda a un público amplio $^{24}$ y llamó cierta atención a nivel nacional. Por ejemplo, a fines del segundo decenio del siglo Xx, aparecieron dos artículos sobre Lola Casanova en El Universal Ilustrado, ${ }^{25}$ los que se basaron claramente en el texto de Hernández, ${ }^{26}$ pero cuya perspectiva, ya posrevolucionaria, se distancia del positivismo porfiriano. El primer artículo, "Lola Casanova, la reina de los seris: un curioso sucedido en Sonora, muchos años ha"

${ }^{24}$ El tomo, de hecho, es grande y elegante, con ilustraciones de color; es un libro caro dirigido a un reducido público especializado. Pero su promoción por el distinguido literato Juan de Dios Peza (ver las primeras páginas del libro, "Dos artículos relativos a esta obra”, sin paginación) le garantiza un público de lectores que va más allá de los letrados sonorenses.

25 Agradezco a Danny Anderson por informarme de la existencia de estos dos artículos y por ayudarme a conseguirlos.

${ }^{26}$ Reiteran casi todos los detalles que menciona Hernández y hasta citan el mismo año erróneo de 1854 como fecha del rapto de Lola. 
de Miguel López, publicado en febrero de 1918, relata la historia ya no como testimonio de una mujer poco educada, sino como "historia, enteramente verídica". Templa un poco las descripciones de la barbaridad de los seris, pero no cambia la perspectiva fundamental: "De civilizada que era tomó las costumbres y ritos bárbaros de la tribu". Ya no emplea la palabra "hembra" para animalizar a la mujer. En cambio identifica la irracionalidad de las acciones de Lola como "muestra de lo complejo de la psicología femenil, del cariño y el martirio de madre, del misterio que envuelve a ese delicado ser llamado mujer". ${ }^{27}$

El segundo fue atribuido al "Licenciado Vidriera" y se publicó bajo el título "Escenas de la vida nacional: Una mujer blanca, reina de los seris: El rapto de Lola Casanova” en julio de 1920. Este artículo toma una posición a la vez más romántica y más hiperbólica en su actitud antiindígena. Su párrafo preliminar asevera: "Los seris son los indios más salvajes y sanguinarios de la América; en la actualidad llevan una vida pacífica bajo la constante vigilancia del Gobierno" (14). ${ }^{28}$ Poco después, el autor clasifica junto con los temidos yaquis, mayos y seris a los ópatas y los pápagos como "indios salvajes" que "fueron un constante peligro para los viajeros" (14). La afirmación de que su relato es "absolutamente verídico" (14) se desmiente en el primer párrafo ya que estas últimas dos tribus, pacificadas desde hace siglos, no se consideraban salvajes en el siglo XIX. ${ }^{29}$ Lola, simplemente "una joven de dieciocho años" en Hernández se convierte en una mujer de hermosura excepcional: "Alta y garrida, blanca, de cabellos dorados y ojos azules, era una rara belleza” (14). Carlos Mérida, recién llegado a México de su país natal Guatemala, provee una curiosa ilustración de Lola en un estilo muy de los años veinte (15; ver Figura 1). La decisión de ésta de quedarse con los seris es producto de "el amor que sentía por su esposo y sus sentimientos materna-

${ }^{27}$ Hay ciertas semejanzas entre el comportamiento de Lola según su leyenda y el de los que padecen del llamado Síndrome Stockholm. Condición atribuida a unos rehenes en un robo bancario en Stockholm en 1973, el síndrome refleja la tendencia de parte de ciertas víctimas de violencia o terrorismo a compadecerse y hasta aliarse con los que los aterrorizan. Ver Ochberg y Soskis.

${ }^{28}$ No queda muy claro a qué gobierno quiere halagar el autor: la falta de gobierno estable durante la revolución hubiera imposibilitado una "constante vigilancia" a una tribu tan "salvaje y sanguinaria" en esta época.

${ }^{29}$ La diferenciación entre los pueblos indígenas de Sonora en cuanto a sus relaciones con los criollos se ve claramente desde el siglo XVIII (ver Radding). 


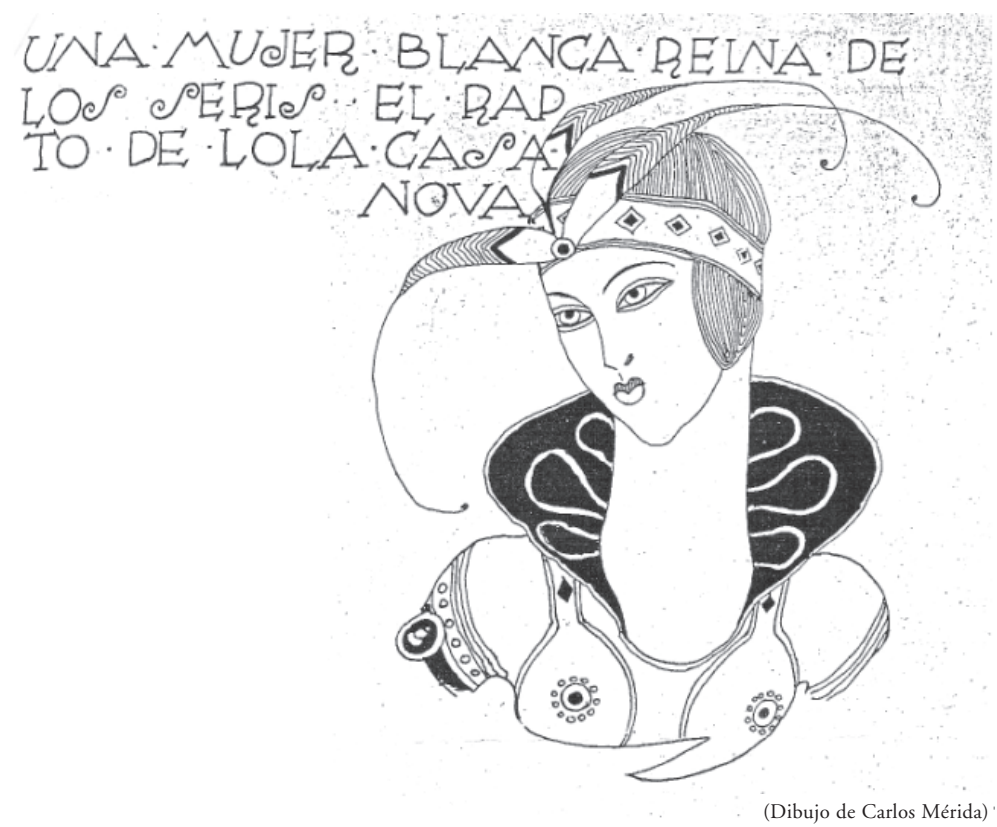

Figura 1

les" (15). La historia se extiende ahora a dos páginas, y este nuevo toque romántico (ya no es testimonio histórico ni curiosidad de la historia regional fronteriza, sino un romance) presagia la conversión de la anécdota en novela.

Poco después, los cambios ideológicos, producto de la revolución, dieron un nuevo lugar a lo indígena en la cultura nacional que fomentaron. Las obras influyentes de Manuel Gamio y José Vasconcelos difundieron el nuevo indigenismo liberal que, entre otros proyectos, ambicionaba reincorporar la gloria de las culturas prehispánicas al imaginario nacional, primero por el muralismo y después por la literatura y el cine. El indigenismo en estos años asumió formas múltiples pero tendía a seguir las paternalistas visiones decimonónicas de las culturas indígenas que las calificaban como primitivas, pero inocentes: gloriosas y nobles, pero sumamente incompatibles con la modernidad y categóricamente incapaces de aproximarse a ella a solas. La asimilación y la modernización de los pueblos indígenas por medio de la educación fue uno de los principios directores de la época. 
No quiero divagar con un análisis detallado de cómo se realizaba el indigenismo cultural en sus productos más conocidos de esta época, tales como la novela El indio (1935), de Gregorio López y Fuentes o la internacionalmente exitosa película María Candelaria (1944), dirigida por Emilio "el Indio" Fernández. Sólo señalo que en estas obras las representaciones de los conflictos entre la cultura nacional mexicana y sus márgenes indígenas seguían recalcando una visión binaria de civilización (el hombre moderno) y barbarie (el noble salvaje), y que el tema de la violación de ésta (en forma de mujer indígena) por aquélla (hombre blanco) seguía repitiéndose. ${ }^{30}$

Sin embargo, es en el dominio de la literatura y del cine donde - de bido al nuevo estatus de lo indígena en la producción cultural mexicana- Lola Casanova se asoma por primera vez en un contexto nacional. La primera representación literaria y no histórica —aunque al fin y al cabo no hay grandes diferencias entre los dos géneros en este caso- de la leyenda es el libro Dolores o la reina de los kunkaks, escrito por Carmela Reyna de León y publicado en Pitiquito, Sonora, en 1943. Se identifica en la portada como "novela histórica basada en el rapto de Dolores Casanova a fines del siglo pasado”.

Según Edith Lowell, la novela de Reyna de León se basa no sólo en la conocida versión de Fortunato Hernández sino también en fuentes seris. Emplea palabras en seri que parecen ser transcripciones hechas por la autora ya que no siguen las formas de vocabularios publicados (Lowell 153: 156). Es, según Lowell, una versión híbrida (seri-mexicana) y es una lástima que la novela no se haya tomada en serio. Ya sea por su estilo romántico, ya no de moda en los años 40 , o por su contexto regional y no nacional, o más probablemente por el hecho que la autora fue una mujer, la novela no se menciona en ninguna historia literaria. ${ }^{31}$

${ }^{30}$ Una variación del paradigma que queda por analizarse de esta perspectiva se halla en El resplandor, novela de 1937 de Mauricio Magdaleno, colaborador guionista de Emilio Fernández. El mestizaje en esta novela se construye como aberración de la revolución mexicana en forma de la violación sexual de una mexicana blanca de medios humildes por un soldado federalista indígena. Magdaleno, en su novela ya casi olvidada, complica la dualidad simplista del malinchismo en maneras interesantes que merecen exploración detallada, aunque ésta va más allá de los propósitos del presente análisis.

31 Tal es el caso con las historias literarias más conocidas, como las de Jiménez Rueda o Brushwood. Se excluye también de los estudios de literatura escrita por mujeres (Robles) y literatura regional de Sonora (Rocha). 
En Dolores, el rapto de Lola acontece en al año 1879 (y no en 1854, como asevera Hernández, ni en 1850, año cuando se menciona por primera vez en las cartas de Cayetano Navarro y los reportajes de El Sonorense). Curiosamente, Lola ya no es criolla, sino una "hermosa mesticita" (Reyna de León: 1). Comparable con el caso de Ramona, otra mestiza americana que se enamora de y se casa con un indígena en la novela estadounidense de Helen Hunt Jackson de 1884, vuelta novela latinoamericana con la traducción de José Martí en 1887, ${ }^{32}$ quizás resulta más creíble que una mestiza y no una blanca se conforme con una vida indígena. También se agrega el detalle de que su amante indígena, aquí llamado Valiente, habla español. Dice éste: "Yo me crié con los blancos, estuve en la escuela en Hermosillo" (8). Como Alejandro en Ramona, el héroe seri no es un indio salvaje - es una figura híbrida, de raza indígena pero de educación criolla-.

La postura que exhibe Dolores Casanova respecto a los indígenas también es ambigua. Por un lado, en los primeros días de su cautiverio, le habla a Valiente de las grandes proezas de ciertos hombres ilustres en la historia mexicana: "debes saber quien es Juárez, Altamirano y Don Ignacio Ramírez, los indígenas han dado pruebas de tener muy buena inteligencia" (22); por otro lado, prefiere no pensar en su futuro amado como indio: "yo he oído decir que la raza de los kunkaaks no es indígena. Con frecuencia, cuando observo la perfección de tus rasgos fisonómicos... me parece que no son en nada parecidos a las otras razas, son en todo iguales a los europeos con la diferencia de color" (23). ${ }^{33}$ Cuando finalmente se casa Lola, se dedica a aprender sus costumbres y llega a entender por qué los seris no quieren "civilizarse" (33). Sin embargo, Lola no es capaz de vivir como salvaje. Al describir su "casa”, el narrador relata: "no era el xacal improvisado, era una casa arreglada lo mejor que se había podido en aquel medio: amplia, limpia, elegante; pues alfombrada con piedras preciosísimas de lobo marino y de alcatraz y sus bancos de vértebras de ballena" (36).

Aunque esta hija de rico comerciante español, reina de carnaval que gozaba de las atenciones de "mil admiradores" (1) no pudiera romper totalmente con su vida lujosa, y aunque fuera su jacal alfombrado el

\footnotetext{
32 En su prólogo, Martí la llama "nuestra novela", es decir, novela de nuestra América (ver Gillman).

${ }^{33}$ Los seris son un subgrupo del pueblo que se llama el konkaak.
} 
más lujoso de la Isla del Tiburón, al fin y al cabo la novela trata de la asimilación de ella, mujer que se aleja de la cultura criolla mexicana. Ocho años después de su rapto, los federales vienen por ella, la convencen que regrese con su familia, pero una vez allí, los niños blancos maltratan a su hijo. Los prejuicios de la sociedad blanca le son menos aguantables que la vida salvaje de la sociedad seri. Finalmente, Valiente la rescata y la historia romántica termina con la reunión feliz de la pareja en la Isla del Tiburón donde a Valiente le nombran rey y a Dolores su reina.

Esta versión, como ya se ha mencionado, no tuvo gran impacto en el ámbito nacional; ni siquiera llamó atención entre los letrados provincianos de Sonora, aunque seguramente habría impactado en sus lectores. Es una novela simple pero bien escrita, sentimental pero sin exageración excesiva, y aparentemente bien investigada — es una lástima que ya no se consiga-.${ }^{34}$ Cuatro años después de su edición, se publicó otra novela que llevó la leyenda a un público mucho más amplio y a un estatus de mucho más prestigio. En 1947, el conocido antropólogo y literato Francisco Rojas González publicó su novela Lola Casanova. Su versión de la leyenda, claramente basada en el reportaje de Fortunato Hernández, no fue una de las obras maestras de su generación, pero el hecho de que fuera escrita por un autor ya conocido, hasta premiado, en el ambiente literario nacional, le ganó un nivel de atención fuera del alcance de una escritora sonorense desconocida en los años 40.

Sin embargo, no se conoce como la mejor obra de su autor. El crítico Joseph Sommers escribe:

La improbabilidad del argumento central, con su exótico contraste entre una mujer muy educada y un ambiente primitivo, lo hace eminentemente apropiado para leyenda, relato romántico o película melodramática. Por otra parte, el detalle etnológico que asoma al describir la vida de los seris delata la mano del indigenista. Ambos elementos, yuxtapuestos, generan una incongruencia que echa a perder la novela (96-97).

El elemento más exótico de la trama, el más incompatible con las metas etnográficas del autor, es decir, el más chocante con el indigenis-

${ }^{34}$ El único ejemplar que se localizado se halla en los archivos del Instituto Nacional de Antropología e Historia de Hermosillo. 
mo oficial y más insólito para una novela cuyo realismo debe de verificarse en el imaginario nacional del momento, es el protagonismo de Lola Casanova, la mujer blanca — y en Rojas González, Lola vuelve a ser "blanquísima" - (11) que abandona la civilización por la barbarie.

En el contexto ya nacional, el único que le interesa a Rojas González, la historia romántica regional se transforma en alegoría nacional. Reyna de León también hizo sus referencias a Benito Juárez, y en su Dolores, cuando Lola abandona Guaymas por segunda vez, su madre busca de nuevo la ayuda militar, pero el soldado encargado le dice: "En la República todos nacen libres. Ella es mayor de edad, si quiere ser salvaje, que lo sea” (Reyna de León: 47). Lola, con su libertad, se separa de la cultura nacional para unirse con una cultura ajena. Si hay alegoría nacional en Reyna de León es una alegoría sobre la fragmentación nacional ante la diversidad racial. Es más fácil que Lola se asimile con los seris que viceversa.

En Rojas González, en cambio, el amor interracial se enlaza firmemente con el concepto de mestizaje, el cual se presenta como solución al problema mexicano del indígena: un mestizaje "basado en el respeto mutuo de la tradición cultural y en el común esfuerzo cooperativo para construir una sociedad moderna" (Sommer: 98). Lola, en Rojas González, ya no es una doncella enamorada que encuentra menos prejuicios entre los seris que en la alta sociedad criolla, sino un símbolo de unidad interracial a nivel nacional.

Por lo tanto, en la novela de Rojas González, el prejuicio sí se encuentra entre los criollos. Esto se demuestra en una escena que sucede años después del rapto de Lola en la que unos seris, entre ellos la ya aculturada protagonista, pasan por Guaymas, donde tienen un breve encuentro con un niño blanco y su madre: "La dama interrumpe su paso, pero de pronto lo reanuda: ha fruncido la frente, a la vez llevado su pañuelito bordado hasta sus narices. 'Vamos, hijo mío, que estas gentes apestan...”' (251-252). Momentos después, Lola se da cuenta de que reconocía a esta mujer de su niñez: había sido su mejor amiga. La alegoría nacional es simple: la amiga representa la ignorancia y la crueldad; Lola es la simpatía y la generosidad. Y es obvio a cuál de las dos necesita la nación.

En cambio, mientras que hay tensiones también entre los seris con respecto a la presencia de una mujer blanca en la tribu, entre Lola y los seris existe la posibilidad, aunque sea incómoda, de convivir y de cono- 
cerse. De esta manera la heroína sirve como instrumento de aculturación. Lola les proporciona a los seris sus conocimientos de la medicina. También aboga por abrir relaciones comerciales con los yoris para cultivar la cooperación intercultural en lugar de la pugna. Como encarnación invertida del embustero híbrido poscolonial de Homi Bhabha ${ }^{35}$ Lola se acomoda en la cultura seri y le introduce sutilmente elementos de la cultura mexicana criolla.

Termina la novela en el siglo xx, en un lugar llamado Pozo Coyote, fundado por los seris que estaban dispuestos al cambio fomentado por Lola, y abiertos al mestizaje, evidenciado por el hecho de que allí llegaban también mestizos para trabajar y convivir. Los seris más conservadores se quedaban en la Isla del Tiburón viviendo primitivamente en el aislamiento. Lola, por supuesto, está con el primer grupo, el grupo del porvenir, pero también el grupo de asimilación, una asimilación idealizada, no destructiva: "Los viejos mueren sin dejar de ser seris; los adultos envejecen tirando hacia yoris; los niños maduran como mestizos... Sin embargo, la tierra, 'abuela de los kunkaaks' y la 'comadre' luna conservan respetabilidad y acatamiento, porque si la gente habla, viste y come yori, en cambio no ha dejado de sentir, de gozar y de sufrir como seri” (268).

Esta revisión de la leyenda presenta a su protagonista de una manera menos radical que en Hernández. No es la mestiza que se enamora del héroe medio ladino de la novela de Reyna de León, pero tampoco idealiza Rojas González la cultura premoderna de los seris. El proyecto de indigenismo exige que Lola sea un puente cultural que los "indios bárbaros" atraviesan para entrar en la nación moderna. La historia sigue siendo inquietante, sin embargo, por el hecho de que Rojas González no se atreve a volcar el desenlace final de la leyenda: es decir, Lola sigue siendo la mujer que abandona su vida en Guaymas para "ser salvaje".

El proyecto de Rojas González tiene muchos elementos interesantes no sólo en cuanto a su elaboración detallada de costumbres indígenas sino también respecto al papel de la mujer, pero las metas muy particulares del indigenismo nacionalista, un indigenismo que finalmente despreciaba la cultura indígena y que todavía no había incorporado

${ }^{35}$ El ser híbrido poscolonial de Bhabha se infiltra en la cultura colonial y la hibridiza subversivamente. 
ningún elemento feminista, evitan que sea una obra realmente vanguardista en términos sociales. Sin embargo, como otra novela de irregular calidad del mismo autor que también exploraba temas de raza y género, La negra Angustias, Lola Casanova le llamó la atención a la primera gran cineasta mexicana, Matilde Landeta, quien produjo su película Lola Casanova, con guión basado estrechamente en la obra de Rojas González, en 1948. ${ }^{36}$

La película sigue la moda del indigenismo cinematográfico de Emilio Fernández y su exitosa película María Candelaria, pero desde la perspectiva -inusitada en la producción cultural mexicana de la época- de una mujer. Escribe la crítica de cine mexicano, Elissa Rashkin: "Landeta intenta incorporar a mujeres de valor en la narrativa maestra de la nación" (48; traducción mía); pero Landeta estaba también muy consciente de la inversión del mito de mestizaje encarnado en sus protagonistas, y ésta también es una razón por la que la directora escogió este texto para su primer largometraje. ${ }^{37}$ Landeta trató de captar el detalle cultural expresado en la novela del antropólogo, pero su presupuesto reducido le limitó sus opciones. El crítico Emilio García Riera asevera:

Por desgracia, la realizadora no pudo ilustrar el tema [...] con un mínimo de verosimilitud. Una cinta que necesitaba de amplios espacios propicios a la acción épica, se desarrolló casi por entero en sets estrechos y muy mal iluminados. En ellos evolucionaban dificultosamente unos personajes cuidadosamente maquillados y muy poseídos por la solemnidad 'exótica' que el cine nacional atribuía a los indígenas al no poder imaginarlos en su vida cotidiana, en sus actitudes más naturales (291). ${ }^{38}$

${ }^{36}$ Después de haber trabajado previamente como mera anotadora, Landeta se lanzó a dirigir Lola Casanova, su primera película, en 1948, seguida por La negra Angustias en 1949.

37 Landeta explica las circunstancias de la producción de Lola Casanova en una entrevista con Isabel Arredondo en 1995. También compara su película ("historia auténtica") con María Candelaria ("una bella ficción”): "Indios auténticos, yo tenía muy pocos, pero en María Candelaria no había ninguno" (197).

38 Refiere Rashkin que Landeta había pensado emplear a seris como extras, pero resultaron demasiado "primitivos" (palabra usada por Landeta misma). "Es decir que los seris verídicos e históricos eran menos adecuados para la tesis de Lola Casanova... que su recreación en los Estudios Churubusco, la que emplearía accesorios auténticos, pero no se sirviría de la experiencia auténtica" (51). 
Los elementos de la producción que quizás más le atrajeron al público, eran los más absurdos. Por ejemplo, el Ballet Nacional de México otorgó a la producción legitimidad artística, pero su baile moderno estilo Martha Graham apenas evoca una cultura "primitiva" a pesar de su vestuario de taparrabos. Aun peor, la actuación de la cabaretera Meche Barba en el papel de Lola resultó risible y sus escenas de amor con Armando Silvestre, quien representó a Coyote Iguana, "sugerían el clásico Me Tarzán, you Jane" (García Riera: 291).

La película, por ser un medio visual, no obstante sus fallas, quizás comunicara con más lucidez el mensaje planteado por Rojas González, un mensaje que convirtió a una protagonista femenina agente en su agenda nacionalista y modernizadora. "Lola Casanova [... ] venía a ser la propia patria criolla o mestiza que compensaba con la entrega amorosa de sí misma la explotación de que los indígenas habían sido objeto por parte del mal hombre blanco. Ella encarnaba el amor, único vehículo que podía incorporar a los seris a la civilización y a la mexicanidad" (García Riera: 291). De ahí el interés de la directora pionera en el personaje. Lo interesante del punto de vista de su directora, no fue entonces el tratamiento del indígena en sí, sino el papel central de la mujer en la cultura nacional. Por este enfoque en lo nacional, repite Landeta la visión no tan radical de Rojas González con respecto a las configuraciones del mestizaje. Lola, fuerza civilizadora y modernizadora de amor, nunca amenaza la cultura criolla que abandona. Revela sus prejuicios y sus consecuencias a veces brutales, pero sigue siendo su representante, su misionera.

Una última versión literaria del mismo año (1948), contesta las de Rojas González y Landeta al asumir una política aun más pro-indio. Armando Chávez Camacho elaboró Cajeme: novela de indios para reivindicar el papel de los indígenas en la historia nacional del noroeste. Cajeme, figura histórica, tiene mucho en común con algunas representaciones de Coyote Iguana, quien muchas veces habla español por haber crecido entre criollos, pero regresa con la gente de su raza para defenderlos ante la violencia criolla. Aunque muchos sonorenses se acordaban de Cajeme como el jefe yaqui en la guerra sangrienta de las décadas de los 1870 y 80, no todos sabían que participó también en el acto patriótico de defender la ciudad de Guaymas cuando la asaltaron filibusteros franceses en 1854. La participación del joven estudiante José María Leyva y otros jóvenes de la preparatoria pública de Guay- 
mas no siempre se cuenta ya que el mismo joven —quien después adoptó el nombre Cajeme, palabra yaqui que quiere decir "el que no bebe" - se volvió gran enemigo de los sonorenses. ${ }^{39}$

Esta novela no se interesa en el mestizaje sino que se empeña en recontar la historia sonorense desde el punto de vista indígena, en revelar las barbaridades que cometió el estado mexicano contra los pueblos indígenas del noroeste durante el porfiriato, y en agregar nombres como el de Cajeme al panteón de héroes nacionales. Casi como divagación, el autor no se resiste a relatar otra leyenda regional con la que se topó durante sus investigaciones de Cajeme, la de Lola Casanova. Resulta interesante que ella ya no es la protagonista principal; Chávez Camacho titula este capítulo "El gran amor de Coyote-Iguana" (191). Su Lola Casanova, curiosamente, ya es mestiza — si bien de piel blan$\mathrm{Ca}-(196)$.

Su fuente principal era probablemente de nuevo Hernández ya que la novela ubica la acción en 1854 . Otra vez lucha Lola para decidir qué hacer: "¿Cuál era en ella el barniz? ¿El de la civilización o el del salvajismo? [...] Finalmente se impuso el corazón: tuvo que confesarse que amaba a Coyote-Iguana" (207). Este pequeño capítulo, presentado como curiosidad ambiental de la historia principal, la de Cajeme y los yaquis, ya no se explaya en el papel de Lola entre los seris, sino que hace hincapié muy concisamente en la mera posibilidad de escoger la vida "salvaje" de los seris en lugar de la comodidad de la cultura criolla. Nuevamente asume Lola su papel radical rechazando la cultura criolla, pero en 1948, el objeto de crítica no es la nación actual, sino la decimonónica. Los seris, ya casi inexistentes, ya no son una amenaza para nadie. ${ }^{40}$

Quizás ésta sea la razón por la que Lola entró brevemente en la cultura ya no regional sino nacional en los 1940. Se resistió la cultura nacional a recibirla por casi un siglo entero, hasta que ya no hubo dificultades con insurrecciones indígenas, hasta que la nación se había consolidado e incorporado mejor la diversidad racial. En el ámbito de

\footnotetext{
39 Por ejemplo, en Heroina, el autor Aurelio Pérez Peña celebra la victoriosa defensa de la ciudad, y sinecdóquicamente de la nación también, pero no incluye el nombre de Leyva entre sus protagonistas, a pesar de que menciona a otros compañeros mucho menos ilustres de la misma escuela.

${ }^{40}$ Su población en 1941 había bajado a 160; hoy en día hay un poco más de 500 seris (Sheridan: 462).
} 
la cultura nacional de los 1940, Lola — sin importar el que fuera su papel: el de señalar las atrocidades del porfiriato, el de promover la asimilación, o hasta el de celebrar el amor interracial y el rechazo romántico de la civilización- ya no fue, en efecto, mujer tan radical. Era una joven curiosa, protagonista de una leyenda anticuada y tal vez admisible ya en una cultura nacional más simbólicamente diversa que antes.

O tal vez no. Pues, ¿qué pasó a partir de 1948? En 1950, Octavio Paz publicó El laberinto de la soledad, reiterando el papel de la leyenda de la Malinche como mito fundacional de la cultura nacional. Para finales de los años 40, ya casi había pasado de moda el indigenismo cinematográfico — si bien sobrevivía en las novelas de una nuevamente resurgente literatura mexicana, más notablemente en la novela Balún Canán de Rosario Castellanos en 1957 y luego en Los hombres verdaderos de Carlo Antonio Castro de 1959-. Pero Lola Casanova no se asomó en Paz, ni fue consagrada en la literatura del boom.

Hoy en día las novelas sobre Lola están fuera de edición y sólo la de Rojas González se consigue con relativa facilidad. Asimismo las películas de Landeta se conocen únicamente entre aficionados del cine de la época dorada y se encuentran sólo con dificultad. Desde 1948, Lola ha sobrevivido esencialmente en forma de leyenda local en Sonora, donde parece que todo el mundo la conoce - hasta los seris, quienes siguen contando sus versiones orales. El estudio definitivo de Edith Lowell recorre las varias mutaciones de la leyenda, todas en fin de cuentas variaciones de la inversión del mito malinchista de mestizaje.

Lowell transcribe dos versiones seris de la leyenda, éstas originalmente grabadas por Edward Moser en 1963. Las dos historias se enfocan no en Lola sino en Coyote Iguana. Se inician con su nacimiento y terminan con su muerte. No obstante, Lola desempeña un papel clave en ambas. La diferencia más significativa entre estas versiones y las anteriores es que las leyendas seris no presentan conceptos tan peyorativos de la otredad; es decir, que no hay pugna entre civilización y barbarie para los seris. Obviamente, Lola es diferente - por ejemplo cuando llega a la Isla del Tiburón-: "Algunos de los seris en la isla nunca habían visto a gente blanca y quedaron pasmados al verla" (Lowell: 148). ${ }^{41}$ Pero cuando ella decide quedarse con Coyote Iguana,

${ }^{41}$ Los informantes le contaron la historia a Moser en seri y español; Lowell 
la leyenda seri no asume las connotaciones peyorativas de la versión de Hernández y sus seguidores. Por ejemplo, al relatar una excursión que hizo Lola a Guaymas después de haber vivido unos años con los seris, cuentan los informantes seris de Lowell: "Andaban por la ciudad y en la tarde volvieron a las afueras [...] Un mexicano vio a Lola y le dijo, 'Usted no es seri, ¿verdad?' Pero Lola no le respondió. Cuando los seris regresaron a Tiburón, Lola volvió con éstos" (Lowell: 151; traducción mía). El aspecto más curioso de estas versiones, que en general comparten muchos detalles con la versión de Hernández que sirve como base de todas las demás versiones "mexicanas", es decir, no seris (Lowell: 147), es el hecho de que los soldados finalmente van por Lola y se la llevan, embarazada, a Guaymas. El regreso de Lola a Guaymas sucede en contra de su voluntad, y deja a su hijo, Víctor, con su marido seri. ${ }^{42}$

El papel de Lola en este contexto parece ser doble. Primero, Lola fue botín de batalla, símbolo de victoria. Coyote Iguana la ganó en una de las escaramuzas constantes entre los seris y los criollos. Segundo, Lola fue la madre fundacional del mestizaje en la nación seri. No se habla de cambios culturales iniciados por Lola, figura marginal porque según los seris sólo se quedó por unos años y nunca aprendió su idioma. Tampoco simboliza una superioridad militar o cultural de los seris, ya que Lola acaba con los soldados blancos.

De todas formas, estos mitos seris sobrevivieron sólo en esta pequeña comunidad — de unos 355 individuos en 1970 (Lowell: 144), y en el folklore local de Hermosillo y Guaymas. Lola sigue siendo icono fronterizo en Sonora, pero nunca - a pesar de los mejores esfuerzos del indigenismo liberal posrevolucionario- logró aceptarse en el imaginario nacional. Mientras que otras leyendas fronterizas como la de la Santa de Cabora han sido reanimadas en años recientes, ${ }^{43}$ el imagina-

publicó la traducción al inglés (presumiblemente de Moser), así que esta versión en español es traducción mía del inglés.

${ }^{42}$ Estos acontecimientos son constantes en tres distintas fuentes seris de la leyenda que cita Lowell, todas de los años 50 y 60 (156-57).

${ }^{43}$ Brianda Domecq publicó La insólita historia de la Santa de Cabora en 1990, la que fue traducida al inglés y publicada en los Estados Unidos unos años después. Teresa Urrea, la legendaria Santa de Cabora también fue inmortalizada en la novela Tomóchic, de Heriberto Frías, novela todavía disponible en varias ediciones, leída y estudiada con frecuencia, y considerada la novela precursora de la novela de la revolución mexicana. 
rio mexicano ha sido terco en su insistencia en la Malinche como la madre mexicana y en su resistencia al intercambio cultural con los pueblos indígenas - y no la aculturación y asimilación unidireccional- a nivel simbólico.

Del mismo modo, la historia de la frontera noroeste mexicana, de interés marginal al discurso nacional en México, no recibe prácticamente ninguna atención en los Estados Unidos, no obstante el gran interés académico en the borderlands. Lola Casanova, a pesar de ser producto de los conflictos culturales transamericanos que definieron la época para la región, nunca ha llamado la atención en Estados Unidos donde la frontera (borderlands) acaba en la frontera (border) geopolítica. Igual que las construcciones nacionales de mestizaje, las chicanas también recurren a la Malinche, ligando una vez más su pasado indígena con la feminidad. En su construcción de un "nuevo mestizaje", Gloria Anzaldúa recurre una y otra vez a la Malinche, a Tonantsi [sic], a Coatlicue, es decir a iconos femeninos, para representar la herencia indígena. Una vez más, la unión entre mujer blanca y hombre indígena queda afuera.

Han pasado muchísimos años desde el rapto de Lola y también desde sus últimas representaciones en la cultura nacional. La lucha zapatista es evidencia de que las cuestiones de racismo y exclusión cultural siguen siendo grandes problemas en México, y la idea de una transculturación que implica intercambio entre el mundo moderno del occidente y el "primitivo" de los indígenas mexicanos y la noción del amor interracial entre mujeres blancas o mestizas y hombres indígenas, siguen siendo inquietantes en una cultura que se define como mestiza, que reconoce cada vez más su hibridez y su heterogeneidad multitemporal ${ }^{44}$ pero que todavía no sabe cómo incorporar a los múltiples pueblos indígenas en la cultura nacional de una manera que les ceda autonomía y reconozca su legitimidad como participantes en la nación moderna o posmoderna. El papel paternalista del indigenismo sigue muy presente en la cultura nacional, y por eso la Malinche, símbolo de la conquista sobre los aztecas y de la subordinación racial, sigue siendo icono nacional de grandes proporciones. Lola Casanova, símbolo de la insurgencia indígena, de la lucha entre las culturas y del peligro de

${ }^{44}$ Se aplican aquí los términos definidos y explorados por Néstor García Canclini en Culturas híbridas. 
la transculturación multidireccional para las clases dominantes, sigue relegada al papel de una mera curiosidad regional. ${ }^{45}$ No obstante las relecturas recientes de la Malinche ${ }^{46}$ la alegoría mexicana del mestizaje sigue grabada en forma inflexible en el imaginario nacional.

\section{BiBLIOGRAFÍA}

Aldaco Encinas, Guadalupe Beatriz. "La prensa decimonónica sonorense: el caso de La Voz de Sonora y La Estrella de Occidente (1856-1870)", en Memoria: XIV simposio de historia y antropología de Sonora. Hermosillo: Instituto de Investigaciones Históricas, Universidad de Sonora, 1990. 361-73.

Altamirano, Ignacio Manuel. El Zarco [1901]. México: Porrúa, 1995.

ARREDONDO, IsABEL. "'Tenía bríos y, aún vieja, los sigo teniendo': entrevista a Matilde Landeta”, en Mexican Studies/Estudios Mexicanos 18.1. (2002).

BARTRA, ROGer. La jaula de la melancolia: identidad y metamorfosis del mexicano. México: Grijalbo, 1987.

Внавна, Номі. The Location of Culture. London: Routledge, 1994.

Blanco, José Joaquín. Crónica literaria: un siglo de escritores mexicanos. México: Cal y Arena, 1996.

Bonifaz de Novelo, María Eugenia. "La frontera en la segunda mitad del siglo XIX, 1850-1870: el noroeste: Sonora”, en David Piñera Ramírez (coord.). Visión histórica de la frontera norte de México, IV: De la nueva frontera al porfiriato [1987]. Mexicali: Universidad Autónoma de Baja California / El Mexicano / Editorial Kino, 1994.

Brushwood, John. México in Its Novel: A Nation's Search for Identity. Austin: University of Texas Press, 1966.

Campuzano, Juan R. Ignacio Altamirano: Constructor de la nacionalidad y creador de la literatura mexicana. México: Federación Editorial Mexicana, 1986.

Castellanos, Rosario. Balún Canán [1957]. México: Fondo de Cultura Económica, 1994.

Castillo, Debra y María Socorro Tabuenca Córdoba. Border Women: Writing from La Frontera. Minneapolis: University of Minnesota Press, 2002.

${ }^{45}$ Aunque casi todas las fuentes recientes sobre Lola Casanova son de Sonora, la antropóloga española Ana M. Fernández Poncela publicó en 2002 un breve estudio sobre la "función sociocultural y política" de la leyenda de Casanova en el contexto nacional mexicano en una revista mexicana.

${ }^{46}$ Ver, por ejemplo, los ensayos recopilados en Glantz. 
Castro, Carlo Antonio. Los hombres verdaderos. Xalapa: 1959.

Chávez Camacho, Armando. Cajeme: novela de indios [1948]. México: Porrúa, 1967.

Cypess, Sandra Messinger. La Malinche in Mexican Literature: From History to Mit.. Austin: University of Texas Press, 1991.

DomecQ, Brianda. La insólita historia de la Santa de Cabora. México: Planeta, 1990.

Dunn, Christopher. "Desvendando identidades nacionais: os discursos de raça e gênero em Pocahontas e Iracema." Letras de Hoje 32.2 (junio de 1997).

Escobosa Gámez, Gilberto. Hermosillo en mi memoria: crónica. Hermosillo: Instituto Sonorense de Cultura, 1995.

Faery, Rebecca Blevins. Cartographies of Desire: Captivity, Race and Sex in the Shaping of an American Nation. Norman: University of Oklahoma Press, 1999.

Fernández, Emilio. María Candelaria. México: Films Mundiales, 1944.

Fernández Poncela, Ana M. "Lola Casanova y Coyote-Iguana: metáfora fundante de un nuevo orden social". Casa del Tiempo. Época 3.37 (febrero de 2002).

Figueroa Valenzuela, Alejandro. "Los indios de Sonora ante la modernización porfirista”. Cynthia Radding de Murrieta (coord.). Historia general de Sonora, Tomo IV: Sonora moderno: 1880-1929. Hermosillo: Gobierno del Estado de Sonora, 1997.

Frías, Heriberto. Tomóchic [1895]. París: C. Bouret, 1911.

Galaz, Fernando. "Lola Casanova". Archivos del Instituto Nacional de Antropología e Historia, Hermosillo, Sonora. "Artículos históricos" Caja 8225, Expediente 77. 305-306.

Gamio, Manuel. Forjando patria [1916]. México: Porrúa, 1982.

García Canclini, Néstor. Culturas hibridas: estrategias para entrar y salir de la modernidad [1989]. México: Grijalbo, 1990.

García Riera, Emilio. Historia documental del cine mexicano, tomo 3: 1945 1948. México: Ediciones Era, 1971.

Gillman, Susan. "Ramona in Our America”. Jeffrey Belnap y Raúl Hernández (eds.). José Martís “Our America”: From National to Hemispheric Studies. Durham: Duke University Press, 1998.

Glantz, Margo (ed.). La Malinche: sus padres y sus hijos. México: Universidad Nacional Autónoma de México, 1994.

GonzÁlez Acosta, Alejandro. El enigma de Jicoténcal. México / Tlaxcala: Universidad Nacional Autónoma de México / Instituto Tlaxcalteca de Cultura / Gobierno del Estado de Tlaxcala, 1997.

González Navarro, Moisés. Historia moderna de México: el porfiriato: la vida social. México: Hermes, 1957. 
Gruesz, Kirsten Silva. Ambassadors of Culture: The Transamerican Origins of Latino Writing. Princeton: Princeton University Press, 2002.

Hennessy, Alistair. The Frontier in Latin American History. Albuquerque: University of New México Press, 1978.

Heredia, José María. Jicoténcal [1826]. México: Universidad Nacional Autónoma de México, 2002.

Hernández, Fortunato. Las razas indígenas de Sonora y la guerra del Yaqui. México: J. de Elizalde, 1902.

InCLÁn, Luis. Astucia [1865]. México: Porrúa, 1987.

Jiménez Rueda, Julio. Historia de la literatura mexicana [1928]. México: Botas, 1953.

Jones, Kristine L. "Comparative Raiding Economies: North and South". Donna J. Guy y Thomas E. Sheridan (eds.). Contested Ground: Comparative Frontiers on the Northern and Southern Edges of the Spanish Empire. Tucson: University of Arizona Press, 1998. 97-114.

Licenciado Vidriera, El (pseud.). "Una mujer blanca reina de los seris: el rapto de Lola Casanova”. El Universal Ilustrado 4:166 (8 de julio de 1920).

Lomnitz, Claudio. Deep México, Silent México: An Anthropology of Nationalism. Minneapolis: University of Minnesota Press, 2001.

López, Miguel A. "Lola Casanova la reina de los seris: un curioso sucedido en Sonora, muchos años ha". El Universal Ilustrado 1:41, 15 febrero de 1918.

López Yescas, ERnesto. "Ecos franceses en la historiografía de Sonora”. Ignacio Almada Bay (coord.). Francia en Sonora. Hermosillo: Instituto Sonorense de Cultura, 1993. 119-27.

López y Fuentes, Gregorio. El indio [1935]. México: Porrúa, 1983.

Lowell, Edith. "A Comparison of Mexican and Seri Indian Versions of the Legend of Lola Casanova”. The Kiva 35:4, 1970. 144-58.

Magdaleno, Mauricio. El resplandor [1937]. Madrid/Málaga: Anaya \& Mario Muchnik/Ayuntamiento de Málaga, 1992.

Martínez, José Luis. La expresión nacional. México: Consejo Nacional para la Cultura y las Artes, 1993.

Moncado O., Carlos. Dos siglos de periodismo en Sonora. Hermosillo: Ediciones EM, 2000.

Mueller, Roseanna. "From Cult to Comics: The Representation of Gonzalo Guerrero as a Cultured Hero in Mexican Popular Culture". Santiago Juan-Navarro y Theodore Robert Young (eds.). A Twice-Told Tale: Reinventing the Encounter in Iberian/Iberian American Literature and Film. Newark: University of Delaware Press, 2001. 137-148.

Ochberg. Frank M. y David Soskis. Victims of Terrorism. Boulder: Westview Press, 1982. 
Operé, Fernando. Historias de la frontera: el cautiverio en la América hispánica. México: Fondo de Cultura Económica, 2001.

Payno, Manuel. Los bandidos de Río Frio [1891]. México: Porrúa, 1996.

Paz, Ireneo. Amor y suplicio. México: Tipografía de J. Rivera, Hijo y Compañía, 1873.

- Doña Marina. México: Ireneo Paz, 1883.

Paz, Octavio. "Los hijos de la Malinche" [1950]. El laberinto de la soledad. México: Fondo de Cultura Económica, 1989.

Pérez Peña, Aurelio. Heroina: drama histórico nacional en tres actos, en prosa y verso. Guaymas: Tipografía de A. Ramírez, 1897.

Radding, Cynthia. Wandering Peoples: Colonialism, Ethnic Spaces, and Ecological Frontiers in Northwestern México, 1700-1850. Durham: Duke University Press, 1997.

Rashrin, Elissa. Women Filmmakers in México: The Country of Which We Dream. Austin: University of Texas Press, 2001.

Reyna de León, Carmela. Dolores o la reina de los kunkaks. Pitiquito: Impresa Económica, 1943.

Rippy, J. Fred. The United States and México. New York: Knopf, 1926.

Robles, MARTHA. La sombra fugitiva: escritoras en la cultura nacional. México: Universidad Nacional Autónoma de México, 1986.

RochA, GILDA. Sonora: un siglo de literatura: poesía, narrativa y teatro (19361992). México: Consejo Nacional para la Cultura y las Artes, 1993.

Rojas González, Francisco. Lola Casanova [1947]. México: Fondo de Cultura Económica, 1984.

Rotker, Susana. Cautivas: olvidos y memoria en Argentina. Buenos Aires: Ariel, 1999.

Rowe, John Carlos. The New American Studies. Minneapolis: University of Minnesota Press, 2002.

Ruibal Corella, Juan Antonio. Historia general de Sonora, tomo III: Periodo México independiente 1831-1883. Hermosillo: Gobierno del Estado de Sonora, 1997.

Sadowski-Smith, Claudia y Claire Fox. "Theorizing the Hemisphere: Inter-Americas Work at the Interssection of American, Canadian, and Latin American Studies". Compartive American Studies 2:1 (2004).

SÁnchez, Rosaura y Beatrice Pita (eds.). Conflicts of Interest: The Letters of María Amparo Ruiz de Burton. Houston: Arte Público Press, 2001.

Santamaría, Francisco J. Diccionario de mejicanismos [1959]. México: Porrúa, 1992.

Sheridan, Thomas E. Empires of Sand: The Seri Indians and the Struggle for Spanish Sonora, 1645-1803. Tucson: University of Arizona Press, 1999. 
Sommer, Doris. Foundational Fictions: The National Romances of Latin America [1991]. Berkeley: University of California Press, 1993.

Sommers, Joseph. Francisco Rojas González: exponente literario del nacionalismo mexicano. Trad. Carlo Antonio Castro. Xalapa: Universidad Veracruzana, 1966.

Tinker Salas, Miguel. In the Shadow of the Eagles: Sonora and the Transformation of the Border During the Porfiriato. Berkeley: University of California Press, 1997.

Turner, Frederick Jackson. "The Frontier in American History" [1893]. The Frontier in American History. New York: Dover, 1996.

Van Delden, Maarten. “Cómo leer a la Malinche”, en Cypess, 1991.

VASCONCELOS, José. Indología: una interpretación de la cultura iberoamericana [1926]. Barcelona: Agencia Mundial de Librería, 1930.

Voss, Stuart. On the Periphery of Nineteenth-Century México: Sonora and Sinaloa, 1810-1877. Tucson: University of Arizona Press, 1982.

Weber, David J. "American Westward Expansion and the Breakdown of Relations Between Pobladores and "Indios Bárbaros" on Mexico's Far Northern Frontier, 1821-1846. Myth and the History of the Hispanic Southwest. Albuquerque: University of New México Press, 1988.

Weber, David J. y Jane M. Rausch. "Introduction". Where Cultures Meet: Frontiers in Latin American History. Wilmington: Scholarly Resources, 1994.

Zavala, Silvio. "The Frontiers of Hispanic America" [1958]. David J. Weber y Jane M. Rausch (eds.). Where Cultures Meet: Frontiers in Latin American History. Wilmington: Scholarly Resources, 1994. 